\title{
Effect of 7-nitroindazole on the expression of intracellular calcium channels in the kidney of spontaneously hypertensive rats
}

\author{
Barbora Sedlakova $^{1}$, Sona Cacanyiova ${ }^{2}$, Karol Ondrias ${ }^{1}$, Frantisek Kristek ${ }^{2}$ and Olga \\ Krizanova $^{1}$ \\ ${ }^{1}$ Institute of Molecular Physiology and Genetics, Centre of Excellence for Cardiovascular Research, Slovak Academy of Sci- \\ ences, Vlárska 5, Bratislava, Slovakia \\ ${ }^{2}$ Institute of Normal and Pathological Physiology, Centre of Excellence for Cardiovascular Research, Slovak Academy of Sci- \\ ences, Sienkiewiczova 1, Bratislava, Slovakia
}

\begin{abstract}
The spontaneously hypertensive rats (SHR) were fed with nitric oxide synthase (NOS) blocker 7-nitroindazole (7-NI, $10 \mathrm{mg} / \mathrm{kg} /$ day) for 6 weeks and an expression of intracellular calcium channels, SERCA and proapoptotic agents was evaluated in kidney. Treatment of rats with 7-NI resulted in a significant increase in mRNA and protein levels of the IP3 receptors type 1 and type 2, while mRNA levels of the IP3 receptor type 3 remained unchanged. The mRNA of other intracellular calcium channels, ryanodine receptors type 1 and type 2 was also upregulated by 7-NI treatment. Gene expression of the SERCA2a, calcium pump responsible for loading intracellular stores with calcium, revealed increased gene expression due to 7-NI as well. Interestingly, proapoptotic agents caspase 3 and Bax were also upregulated by the 7-NI treatment. These results may indicate that nNOS blocker 7-NI modifies intracellular calcium transport system, which may have impact on altered calcium handling and regulation of various metabolic pathways.
\end{abstract}

Key words: IP3 receptors - 7-nitroindazole - Spontaneously hypertensive rats - Apoptosis

\section{Introduction}

Nitric oxide (NO) is an important modulator of many physiological processes. It is believed that NO modulates cell functions in several signal pathways. Family of mammalian enzymes that produce NO termed nitric oxide synthases (NOS) have been purified, cloned and characterized. Up to now, three genetically distinct NOSs have been identified - neuronal (nNOS), inducible (iNOS) and endothelial (eNOS). NOS enzymes form NO and L-citrulline from the amino acid L-arginine via a complex oxidation-reduction reactions. All NOS isoforms have a high sequence similarity to cytochrome P-450 reductase and are unique because they are not only mammalian proteins that catalyze both

Correspondence to: Olga Krizanova, Institute of Molecular Physiology and Genetics, Centre of Excellence for Cardiovascular Research, Slovak Academy of Sciences, Vlárska 5, 83334 Bratislava, Slovakia

E-mail: olga.krizanova@savba.sk hydroxylation reaction and NADPH reduction (Kelly and Burke 1996).

Numerous animal studies have demonstrated systemic and other effects of NOS blockade using L-arginine analogues (for review, see Zahradníková and Križanová 1997). These blockers inhibit the conversion of L-arginine to L-citrulline in dose dependent manner and most of them are not isoforms-selective. The 7-nitroindazole (7-NI) was developed as a selective inhibitor of NOS in central nervous system (Moore et al. 1993). 7-NI is a widely used inhibitor of nNOS used to study the role of the neuronal NO pathway in the nervous system.

High level of nNOS protein expression was demonstrated in kidney, especially in macula densa cells (Tojo et al. 2000; Mount et al. 2005) where constitutively generates NO and acts, besides others, as a positive regulator of renin secretion (Kihara et al. 1998). Via this effect NO is one of the key substances in the regulation of the renin-angiotensin system (Kihara et al. 1998). In normotensive rats, stimulation of renin secretion was abolished by nNOS blockers (He et al. 
1995). Beierwaltes (1995) showed that 7-NI chronic treatment reversed macula densa stimulation of renin, which is a key enzyme of angiotensin II synthesis. NO produced by nNOS in macula densa cells was also shown to blunt tubuloglomerular feedback (TGF) response which results in an increase in glomerular capillary pressure, and filtration rate (Wilcox et al. 1992). Spontaneously hypertensive rats (SHR) have enhanced TGF responses and it could be associated with diminished role of NO from nNOS in blunting TGF (Welch et al. 2000).

Several calcium transport systems are known to be modulated by NO. The cardiac ryanodine receptor (RyR) is subject for phosphorylation and has several reactive cysteins whose redox state is important for the function of RyR (Pessah and Schiedt 1990). Thus, RyR is a likely candidate for both direct modulation by NO (through modification of thiol groups) or indirect modulation (through the extent of RyR phosphorylation). NO stimulates also the $\mathrm{Na}^{+} / \mathrm{Ca}^{2+}$ exchanger in neuronal preparations and astrocytes via a cyclic GMP-dependent mechanism (Asano et al. 1995; Takuma et al. 1996). Exogenous NO induced the release of calcium from intracellular IP3 receptor-sensitive stores in neutrophils via S-nitrosylation in a respiratory burst-dependent manner (Pan et al. 2008). Also, it was shown that IP3-dependent calcium signaling may enhance local sarcoplasmic reticulum calcium release required to activate calcium-dependent eNOS/NO production from subsarcolemmal calveolae sites (Wang et al. 2006).

Alterations in the above mentioned regulatory systems (NO, TGF, renin-angiotensin system, calcium handling) and the interactions among them seem to be important mechanisms triggering pathological processes leading to spontaneous hypertension. Based on these results we aimed to study whether long-term application of nNOS specific inhibitor 7-NI can affect IP3 receptors, RyRs and sarcoplasmic reticulum $\mathrm{Ca}^{2+}$ ATPase (SERCA) in kidney of SHR. Since IP3 receptors are known to participate in the development of apoptosis (Joseph and Hajnoczky 2007) and NO is also involved in this process, we tried to find out how long-term blockade can affect expression of some proapoptotic factors.

\section{Materials and Methods}

\section{Animals}

Male SHR, 10 weeks old, weighing 290-380 g were used in the experiment. Prior to the experiments, rats were housed for 1 week in a controlled environment $\left(22 \pm 2^{\circ} \mathrm{C}, 12 \mathrm{~h}\right.$ light/ dark cycle, lights on at 6.00 a.m., humidity 45-55\%). Food and water were available ad libitum. All animal experiments presented were approved by The Ethics Committee of the Institute of Normal and Pathological Physiology, Slovak Academy of Sciences, Bratislava, Slovakia.

\section{Administration of 7-nitroindazole}

From the $10^{\text {th }}$ week of their life, rats were treated with 7 -NI in the dose of $10 \mathrm{mg} / \mathrm{kg} /$ day in drinking water for 6 weeks. This dose represented the most commonly used dose of 7-NI that is dissolved in drinking water and has been found to inhibit nNOS in vivo (Moore et al. 1993; Wangensteen et al. 2003). Since higher doses of 7-NI inhibit also other forms of NOS (Benyó et al. 2000; Ayajiki et al. 2001) we did not use higher doses of 7-NI to avoid the non-specific (indirect) effect. The uptake of 7-NI was monitored daily. The concentration of the compound in the drinking water was adjusted every day in experimental groups according to their respective drinking intake. The other group represented control rats. After the end of the experiment, rats were decapitated, both kidneys were removed, cleaned from fat, and each kidney was wrapped and frozen separately in liquid nitrogen. Experiments were performed on right kidney.

\section{$R N A$ preparation and quantification of relative $m R N A$} levels by RT-PCR

Total RNA was isolated with TRI Reagent ${ }^{\circledR}$ (MRC Inc., Cincinnati, OH, USA). Briefly, tissue samples were homogenized with a tissue homogenizer (BioSpec Products Inc., OK, USA) in TRI Reagent ${ }^{\circledR}$ and after 5 min the homogenate was extracted with chloroform. RNAs in the aqueous phase were precipitated by isopropanol. The RNA pellet was washed with $75 \%$ ethanol and stored in $96 \%$ ethanol at $-70^{\circ} \mathrm{C}$. The purity and concentration of isolated RNA was checked with a GeneQuant Pro spectrophotometer (Amersham Biosciences, Buckinghamshire, UK) at 260 $\mathrm{nm}, 260 / 280 \mathrm{~nm}$ and 230/260 nm, respectively. Reverse transcription was performed using $1.5 \mu \mathrm{g}$ of total RNAs and Ready-To-Go You-Prime First-Strand Beads (GE Healthcare Life Sciences) with $\mathrm{pd}(\mathrm{N})_{6}$ primer. PCR specific for the type 1, 2 and 3 IP3 receptors (IP3R1, IP3R2 and IP3R3), RyR type 1 (RyR1) and 2 (RyR2), SERCA2a as well as for proapoptotic factors caspase 3 and Bax were carried out using appropriate primers (Table 1). Glyceraldehyde 3-phosphate dehydrogenase (GAPDH; GI 56187) was used as a housekeeper gene control for semi-quantitative evaluation of PCR. Each PCR program started with initial denaturation at $94^{\circ} \mathrm{C}$ for $5 \mathrm{~min}$, followed by $25 / 30$ (for IP3R1/IP3R2/IP3R3//RyR2/RyR2/SERCA2a) and 38 (for caspase 3 and Bax) cycles of denaturation at $94^{\circ} \mathrm{C}$ for $1 \mathrm{~min}$, annealing at $55-60^{\circ} \mathrm{C}$ for $1 \mathrm{~min}$, and polymerization at $72^{\circ} \mathrm{C}$ for $1 \mathrm{~min}$. PCRs were terminated by final polymerization at $72^{\circ} \mathrm{C}$ for $7 \mathrm{~min}$. PCR specific for GAPDH started by initial denaturation at $94^{\circ} \mathrm{C}$ and was followed by 30 cycles of denaturation at $94^{\circ} \mathrm{C}$ for $1 \mathrm{~min}$, annealing at $60^{\circ} \mathrm{C}$ for $1 \mathrm{~min}$ and polymerization at $72^{\circ} \mathrm{C}$ for $1 \mathrm{~min}$. PCRs were terminated by final polymerization at $72^{\circ} \mathrm{C}$ for $7 \mathrm{~min}$. All PCR products 
Table 1. Sequences of primers, their fragment sizes (nt - nucleotide) and GI of the corresponding gene

\begin{tabular}{|c|c|c|c|}
\hline Primer & Sequence & GI & Fragment size \\
\hline IP3R1 & $\begin{array}{l}5^{c} \text {-GTG GAG GTT TCA TCT GCA AGC-3‘ } \\
5^{c} \text {-GCT TTC GTG GAA TAC TCG GTC-3 }\end{array}$ & 1054962 & $410 \mathrm{nt}$ \\
\hline IP3R2 & $\begin{array}{l}5^{\star}-\text { GCT CTT GTC CCT GAC ATT G-3 } \\
5^{\star}-\text { CCC ATG TCT CCA TTC TCA TAG C-3 }\end{array}$ & 34851153 & $361 \mathrm{nt}$ \\
\hline IP3R3 & $\begin{array}{l}5^{c}-\mathrm{CTG} \text { CCC AAG AGG AGG AGG AAG-3' } \\
5^{c}-\text { GAA CAG CGC GGC AAT GGA GAA G-3' }\end{array}$ & 25679 & $452 \mathrm{nt}$ \\
\hline SERCA2a & $\begin{array}{l}5^{`}-A T T \text { GTT CGA AGT CTG CCT TCT GTG G-3` } \\
5^{`}-\text { CAT AGG TTG ATC CAG TTA TGG TAA A-3 }\end{array}$ & 8392934 & $174 \mathrm{nt}$ \\
\hline RyR1 & $\begin{array}{l}5^{c} \text {-GAC CAA CAA GAG CAA GTC AAG-3‘ } \\
5^{c} \text {-CTC TTC TAG AGT GTG GGT CTC-3 }\end{array}$ & 109461559 & $115 \mathrm{nt}$ \\
\hline RyR2 & $\begin{array}{l}\text { 5'-CAT CGG TGA TGA AAT TGA AGA-3 } \\
5^{`} \text {-AGC ATC AAT GAT CAA ACC TTG-3 }\end{array}$ & 2305245 & $129 \mathrm{nt}$ \\
\hline Casp3 & $\begin{array}{l}5^{c} \text {-AAC TGG ACT GTG GCA TTG-3 } \\
5^{c} \text {-ACC AGG TGC TGT GGA GTA-3' }\end{array}$ & 158256109 & $106 \mathrm{nt}$ \\
\hline Bax & $\begin{array}{l}5^{`}-\mathrm{AGA} \text { GGA TGA TTG CCG CCG-3 } \\
5^{`}-\mathrm{CAA} \text { CCA CCC TGG TCT TGC ATC-3 }\end{array}$ & 16365948 & $223 \mathrm{nt}$ \\
\hline GAPDH & $\begin{array}{l}5^{`} \text {-AGA TCC ACA ACG GAT ACA TT-3 } \\
5^{`}-\text { TCC CTC AAG ATT GTC AGC AA-3 }\end{array}$ & 56187 & $309 \mathrm{nt}$ \\
\hline
\end{tabular}

were analyzed on $2 \%$ agarose gels. Intensity of individual bands was evaluated by measuring the optical density per $\mathrm{mm}^{2}$ and compared relative to GAPDH mRNA.

\section{Western blot analysis}

IP3R1, IP3R2 and caspase 3 proteins were determined in crude membrane fraction from the rat kidney. Protein concentration was determined according to Lowry et al. (1951). Fifty micrograms of protein extract from each sample was separated by electrophoresis on $10 \%$ SDS polyacrylamide gels and proteins were transferred to Hybond ECL membrane using semidry blotting (Owl Separation Systems Inc., Porthsmouth, NH, USA). Membrane was blocked in 5\% nonfat dry milk diluted in TBST (Tris buffered saline-Tween) and then incubated with the appropriate antibody. For the detection of IP3R1, rabbit anti-IP3R1 (Calbiochem, Merck Biosciences, Darmstadt, Germany) was utilized in dilution $1: 1000$. This polyclonal antibody recognized IP3R1. The epitope does not share homology with any other known protein. It is known to react with rat and to recognize a $240 \mathrm{kDa}$ protein. For the detection of IP3R2, rabbit antiIP3R2 polyclonal antibody (Chemicon International Inc., Temecula, CA, USA) diluted $1: 1000$ was used. This rabbit anti-IP3R2 polyclonal antibody reacts with human, rat and mouse. Reactivity with other species has not been determined. For the detection of caspase, rabbit anti-caspase 3 polyclonal antibody (Chemicon International Inc.) was used in dilution $1: 100$. Rabbit anti-caspase 3 polyclonal antibody detects procaspase $3(32 \mathrm{kDa})$ and the cleaved p20 fragment in cells undergoing apoptosis. It reacts with human, mouse and rat.

Horseradish peroxidase linked secondary antibody and chemiluminescence was used for visualization. Signal was detected on Kodak camera. Optical density of individual bands was quantified using PCBAS 2.0 software.

\section{Statistical analysis}

Each value represents the average of 6-7 animals. Results are presented as means \pm S.E.M. Statistical differences among groups were determined by $t$-test. Statistical significance $p<$ 0.05 was considered to be significant.

\section{Results}

Treatment of SHR with 7-NI resulted in significant increase in the mRNA (Fig. 1A) and protein (Fig. 1B) levels of the IP3R1 in the kidney of SHR. In 7-NI-treated rats, the IP3R1 mRNA was elevated from $14.1 \pm 1.0$ to $24.0 \pm 2.9$ a.u. (Fig. $1 \mathrm{~A}, p=0.01$ ). The same effect was observed at the protein levels of the IP3R1 (from 11.6 \pm 2.9 a.u. in the kidney of control rats to $20.3 \pm 0.6$ a.u. in the kidney of 7-NI-treated rats, Fig. $1 \mathrm{~B}, p=0.05)$. The IP3R2 was also increased at mRNA (from $9.7 \pm 1.5$ a.u. in the kidney of control rats to $15.0 \pm 0.9$ a.u. in the kidney of 7-NI-treated rats, Fig. 1C, $p<0.05)$ and protein (from $12.8 \pm 2.5$ a.u. in the kidney of control rats to 

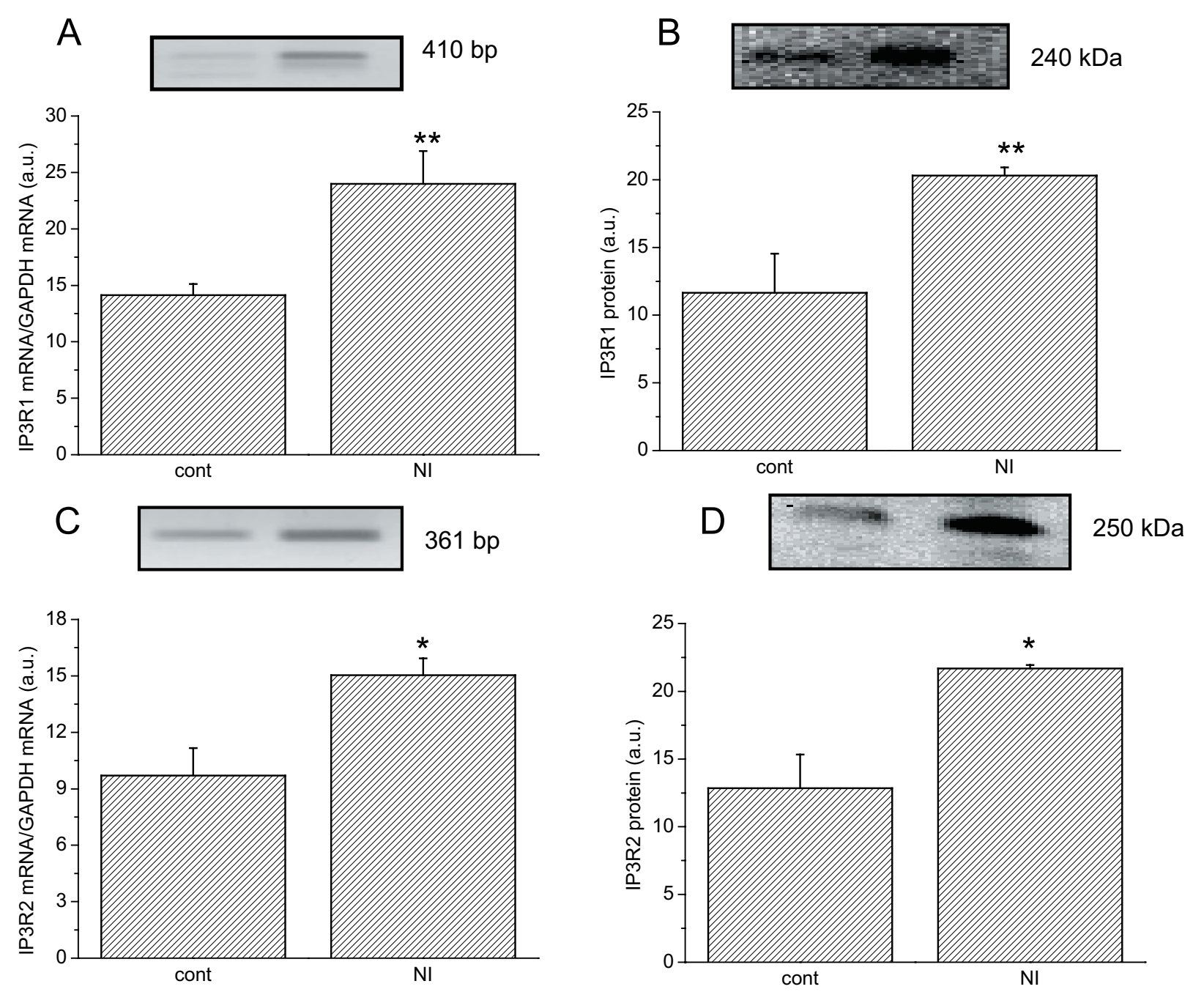

Figure 1. The mRNA (A) and protein (B) levels of the IP3R1 and also the mRNA (C) and protein D) levels of the IP3R2. IP3R1 and IP3R2 mRNA was quantified relatively to the housekeeper GAPDH. cont, control (untreated animals); NI, animals treated for 7 weeks with 7-NI. Each column is displayed as mean \pm S.E.M. and represents an average of at least 5 animals. Statistical significance calculated by $t$-test represents ${ }^{\star} p<0.05,{ }^{\star *} p<0.01$.

$21.7 \pm 0.3$ a.u. in the kidney of 7-NI-treated rats, Fig. 1D, $p<0.05)$ levels. On contrary, IP3R3 gene expression was not changed (Fig. 2A). SERCA2a mRNA levels were increased from $3.0 \pm 0.6$ to $5.3 \pm 0.7$ a.u. (Fig. $2 \mathrm{~B}, p<0.05$ ) in the group of SHR treated with 7-NI. Another type of reticular calcium release channels, RyR1 and RyR2 were also modulated by 7-NI. Gene expressions of the RyR1 was elevated from 0.68 \pm 0.16 a.u. in the kidney of control rats to $2.62 \pm 0.48$ a.u. in the kidney of 7-NI-treated rats (Fig. 3A, $p<0.002$ ) and RyR2 increased from $4.73 \pm 0.52$ a.u. in the kidney of control rats to $7.55 \pm 0.19$ a.u. in the kidney of 7-NI-treated rats (Fig. $3 \mathrm{~B}, p<0.002)$. Increase in endoplasmic reticulum calcium transport systems was accompanied with the increase in expression of proapoptotic agents, caspase 3 and Bax. 7-NI elevated gene expression (from $9.3 \pm 1.1$ a.u. in the kidney of control rats to $16.8 \pm 1.1$ a.u. in the kidney of 7-NI-treated rats, Fig. $4 \mathrm{~A}, p<0.01$ ) and protein levels (from $7.5 \pm 1.2$ a.u. in the kidney of control rats to $14.6 \pm 0.8$ a.u. in the kidney of 7 -NI-treated rats, Fig. 4B, $p<0.05$ ) of caspase 3 in the kidney of SHR and mRNA levels for Bax (from $4.1 \pm 0.9$ to $10.8 \pm 2.0$ a.u., Fig. 4 C, $p<0.05$ ).

\section{Discussion}

In this work we studied how intracellular calcium transport systems, IP3R1, IP3R2, IP3R3, RyR1, RyR2 and SERCA2a are affected by the long-term application of 7-NI in the kidney of 
A

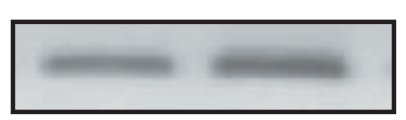

$452 \mathrm{bp}$

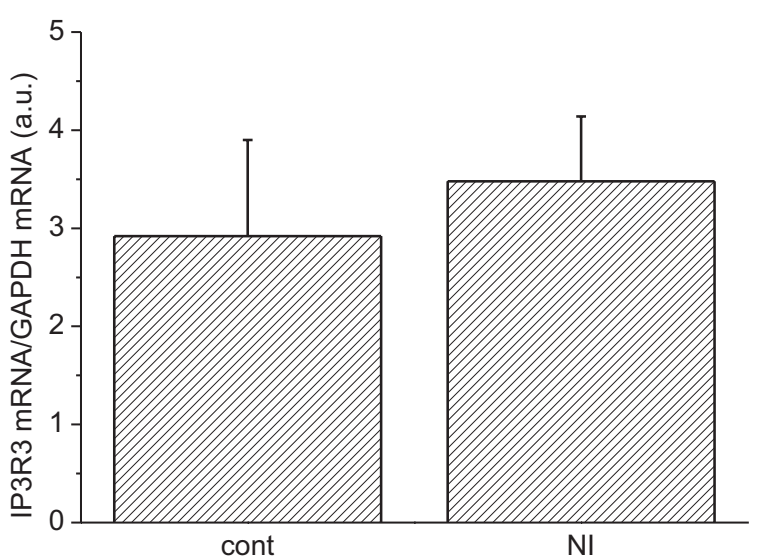

B

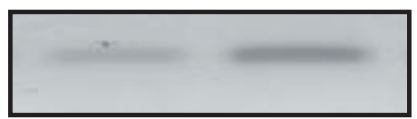

$174 \mathrm{bp}$

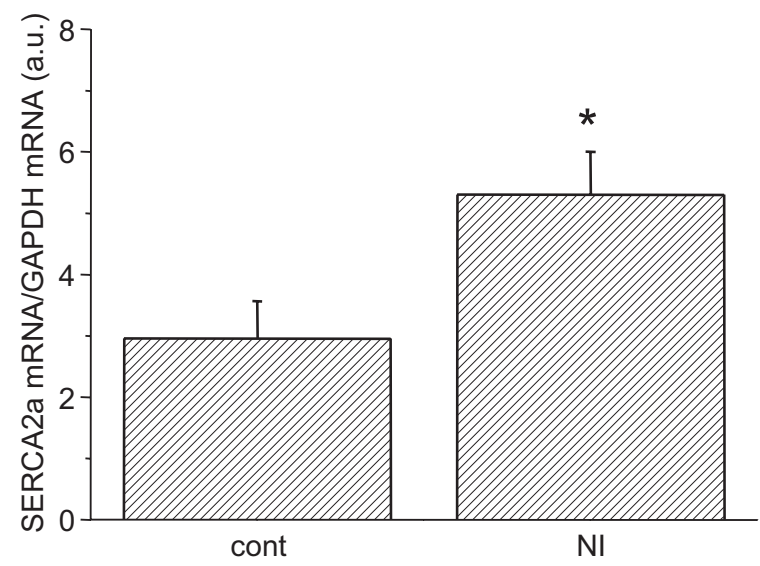

Figure 2. The mRNA levels of the IP3R3 (A) and SERCA2a (B) quantified relatively to the housekeeper GAPDH. cont, control (untreated animals); NI, animals treated for 7 weeks with 7-NI. Each column is displayed as mean \pm S.E.M. and represents an average of at least 5 animals. Statistical significance calculated by $t$-test represents ${ }^{*} p<0.05$.
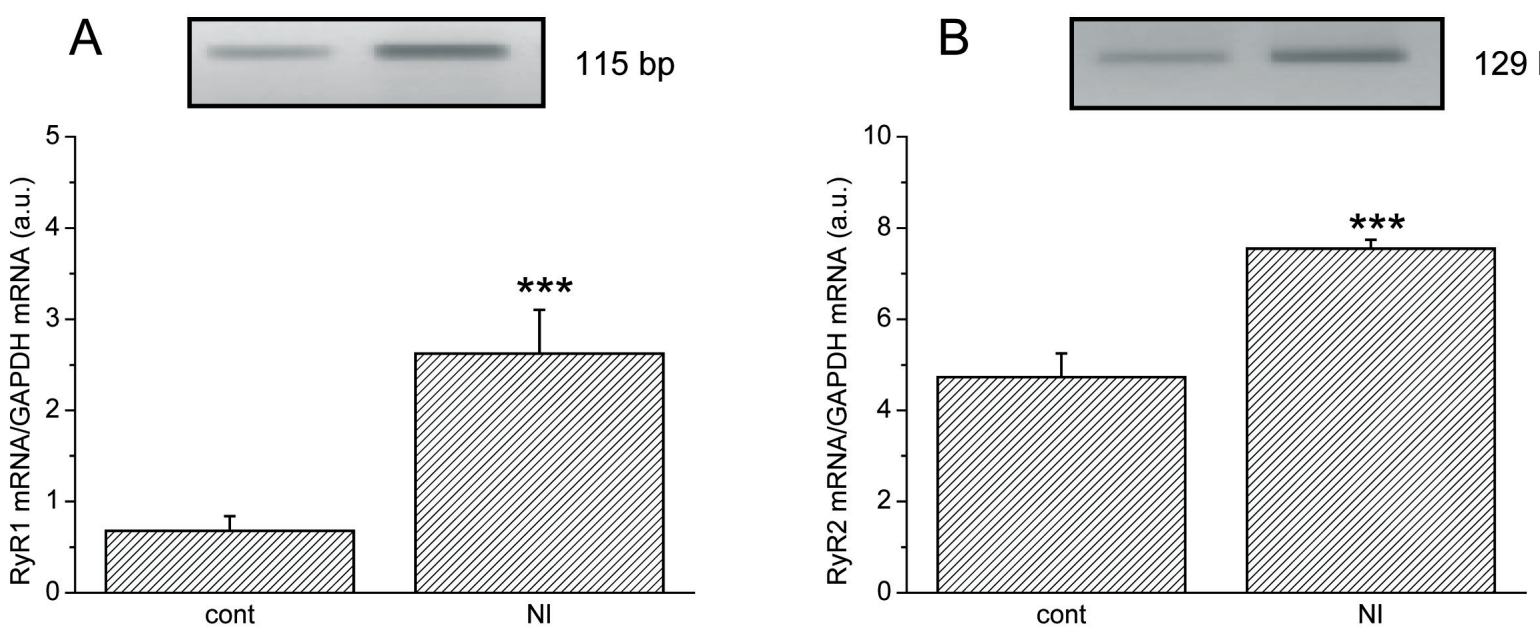

Figure 3. The mRNA levels of the RyR1 (A) and RyR2 (B) quantified relatively to the housekeeper GAPDH. cont, control (untreated animals); NI, animals treated for 7 weeks with 7 -NI. Each column is displayed as mean \pm S.E.M. and represents an average of at least 5 animals. Statistical significance calculated by $t$-test represents ${ }^{* *} p<0.002$.

SHR. The main impact was given on determination, whether increased levels of IP3 receptors due to 7-NI treatment in SHR might result in the induction of apoptosis. We have shown that gene expression and protein levels of the IP3R1 and IP3R2 were significantly increased after 7-NI treatment. The mRNA levels of other types of the intracellular calcium channels, RyR1 and RyR2, were also increased. Also, gene expression of the SERCA2a was upregulated. These results might point to higher importance of calcium transport from the intracellular stores after blocking of nNOS by 7-NI in kidney of SHR.

$\mathrm{NO}$ is implicated in the regulation of renal vascular resistance, glomerular filtration, tubular reabsorption, renin secretion and TGF responses (Welch et al. 2000). TGF is a vasoconstrictive response of the afferent arteriole that reduces the glomerular capillary pressure and the single-nephron glomerular filtration rate during reabsorption of the $\mathrm{NaCl}$ by the macula densa segment. This vasoconstrictive response is 

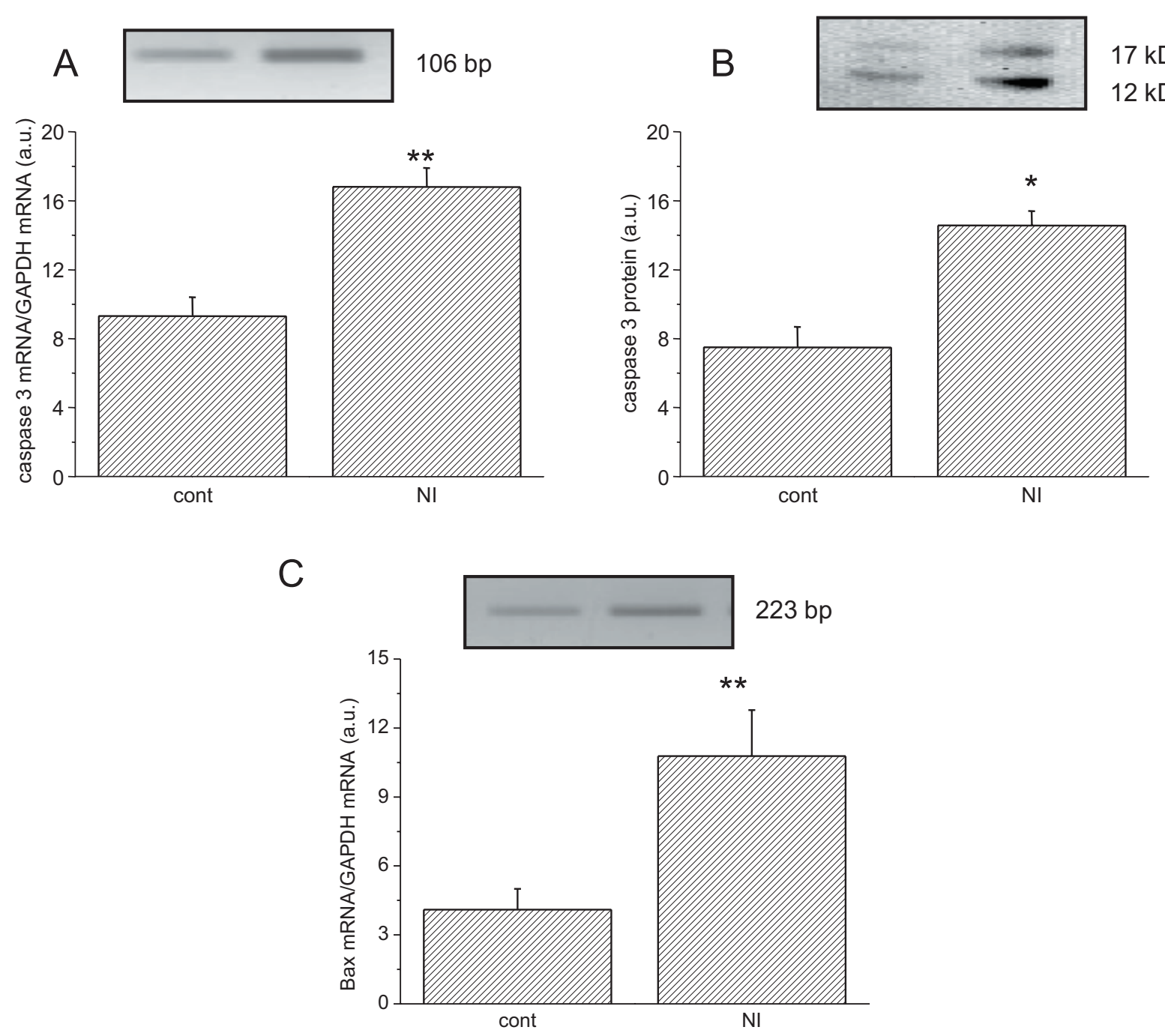

Figure 4. The mRNA (A) and protein (B) levels of the caspase 3 and the mRNA levels of Bax (C). Caspase 3 and Bax mRNA was quantified relatively to the housekeeper GAPDH. cont, control (untreated animals); NI, animals treated for 7 weeks with 7-NI. Each column is displayed as mean \pm S.E.M. and represents an average of at least 5 animals. Statistical significance calculated by $t$-test represents ${ }^{\star} p<0.05,{ }^{*} p<0.01$.

enhanced in the SHR model of hypertension and may contribute to renal mechanisms for the development of hypertension. The nNOS is heavily expressed in macula densa cells. SHR has a diminished or absent TGF response to local inhibition of NOS in the juxtaglomerular apparatus with nitro-L-arginine (Thorup and Persson 1996) or nNOS with 7-NI (Welch et al. 1999). This defect is likely due to NO activity in the macula densa, since SHR failed to respond to 7-NI microperfused into the lumen of the macula densa, whereas robust and consistent responses were seen in the control Wistar-Kyoto rats. Calcium antagonist manidipine was shown to correct hyperactivity of the TGF mechanism in SHR (Takabatake et al. 1993). This points to the link among the inhibition of NO production, calcium and SHR in the regulation of TGF. In macula densa cells, decrease in $\mathrm{NaCl}$ concentration increased intracellular calcium. The increase observed was rather small amounting to $30 \mathrm{nmol} \cdot \mathrm{l}^{-1}$, with the largest slope of calcium increase found between a $\mathrm{NaCl}$ lumen concentration from 70 to $10 \mathrm{mmol} \cdot \mathrm{l}^{-1}$. This is in the range where most physiological events occur, such as renin release and the response from the TGF mechanism (Persson et al. 2004). Increase in the expression of intracellular calcium systems in SHR treated for a long time with 7-NI could be a compensatory mechanism for the regulation of TGF in SHR.

The question remains, what is the physiological relevance of 7-NI-induced gene expression of proapoptotic factors caspase 3 and Bax. It was already found that administration of NOS inhibitor prevents the hypoxia-induced generation of free 
radicals, nitration of the NMDA (N-methyl-D-aspartic acid) receptor subunits, calmodulin kinase IV activation, increased expression of the apoptotic protein Bax, and fragmentation of nuclear DNA (Numagami et al. 1997; Zanelli et al. 2002; Zubrow et al. 2002). Thus, NO can play a role in hypoxia-induced neuronal cell death by the necrotic as well as the apoptotic or programmed cell death mechanisms in normotension. Local actions of $\mathrm{NO}$ at the level of juxtaglomerular apparatus seemed plausible, since NO-generating enzymes are expressed both in endothelial and macula densa cells. Transgenic mice with null mutations in either eNOS or nNOS revealed differences in renin production (Wagner et al. 2000). These findings support the concept that the constitutive production of NO generally enhances renin expression, and that the endothelium is the predominant source of the NO involved in affecting the level of renin expression. Question remains, whether NO production by eNOS can overhelm the NO production by nNOS in kidney.

We assume that also modified intracellular calcium transport systems (especially IP3 receptors) may be responsible for increase in the proapoptotic factors. Increased levels of IP3 receptors are known to induce apoptosis by releasing higher amount of calcium in the vicinity of mitochondria, which activates release of cytochrom $c$ and further caspases and turns on the process of apoptosis (Joseph and Hajnoczky 2007).

It seems that while inhibition of NOs with analogs of L-arginine results in antiapoptotic effect, inhibition of nNOS with 7-NI is proapoptotic (increase in Bax protein and caspase 3). These apparently contradictory results fit well with functional and morphological (Kristek et al. 2009) studies, showing, contrary to L-arginine analogs administration, hypotrophy of the conduit arterial wall accompanied by decrease in norepinephrine-induced contraction after long-term 7-NI administration to normotensive rats. However, the effect of NOS inhibition in the apoptotic processes could be modified by spontaneous hypertension. Sun et al. (2008) showed downregulation of the caspase 3 after 7-NI administration in normotensive rats, while Akashiba et al. (2008) and Ono et al. (1999) demonstrated that L-NAME given to SHR increased caspase 3 expression in the heart indicating proapoptotic effect of NOS inhibition. The results are in a good agreement with our findings concerning proapoptotic effect of nNOS inhibition by 7-NI (increase in Bax protein and caspase 3 gene expression).

Acknowledgement. This work was supported by grants VEGA 2/7123 and APVV 51-0397-07.

\section{References}

Akashiba A., Ono H., Ono Y., Ishimitsu T., Matsuoka H. (2008): Valsartan improve L-NAME-exacerbated cardiac fibrosis with TGF-beta inhibition and apoptosis induction in spontaneously hypertensive rats. J. Cardiol. 52, 239-246; doi:10.1016/j.jjcc.2008.07.018

Asano S., Matsuda T., Takuma K., Kim H. S., Sato T., Nishikawa T., Baba A. (1995): Nitroprusside and cyclic GMP stimulate $\mathrm{Na}^{+}-\mathrm{Ca}^{2+}$ exchange activity in neuronal preparations and cultured rat astrocytes. J. Neurochem. 6, 2437-2441

Ayajiki K., Fujioka H., Okamura T., Toda N. (2001): Relatively selective neuronal nitric oxide synthase inhibition by 7-nitroindazole in monkey isolated cerebral arteries. Eur. J. Pharmacol. 423, 179-183; doi:10.1016/S00142999(01)01068-8

Beierwaltes W. H., Potter D. L., Carretero O. A., Sigmon D. H. (1995): Nitric oxide synthesis inhibition blocks reversal of two-kidney, one clip renovascular hypertension after unclipping. Hypertension 25, 174-179

Benyó Z., Lacza Z., Hortobágyi T., Görlach C. H., Wahl M. (2000): Functional importance of neuronal nitric oxide synthase in the endothelium of rat basilar arteries. Brain Res. 877, 79-84; doi:10.1016/S0006-8993(00)02611-1

He X. R., Greenberg S. G., Briggs J. P., Schnermann J. (1995): Effects of furosemide and verapamil on the $\mathrm{NaCl}$ dependency of macula densa-mediated renin secretion. Hypertension 26, $137-142$

Joseph S. K., Hajnoczky G. (2007): $\mathrm{IP}_{3}$ receptors in cell survival and apoptosis: $\mathrm{Ca}^{2+}$ release and beyond. Apoptosis 12, 951-968; doi:10.1007/s10495-007-0719-7

Kelly W. J., Burke R. E. (1996): Apoptotic neuron death in rat substantia nigra induced by striatal excitotoxic injury is developmentally dependent. Neurosci. Lett. 220, 85-88; doi:10.1016/S0304-3940(96)13216-X

Kihara M., Umemura S., Sugaya T., Toya Y., Yabana M., Kobayashi S., Tamura K., Kadota T., Kishida R., Murakami K., Fukamizu A., Ishii M. (1998): Expression of neuronal type nitric oxide synthase and renin in the juxtaglomerular apparatus of angiotensin type-1a receptor gene-knockout mice. Kidney Int. 53, 1585-1593; doi:10.1046/j.15231755.1998.00904.x

Kristek F., Čačányiová S., Gerová M. (2009): Hypotrophic effect of long-term neuronal NO-synthase inhibition on heart and conduit arteries of the Wistar rats. J. Physiol. Pharmacol. 60, 21-27

Lowry O. H., Rosebrough N. J., Farr A. L., Randall R. J. (1951): Protein measurement withthe Folin phenol reagent. J. Biol. Chem. 193, 265-275

Mount P. F., Fraser S. A., Watanabe Y., Lane N., Katsis F., Chen Z. P., Kemp B. E., Power D. A. (2005): Phosphorylation of neuronal and endothelial nitric oxide synthase in the kidney with high and low salt diets. Nephron. Physiol. 102, 36-50; doi:10.1159/000089092

Moore P. K., Babbedge R. C., Wallace P., Gaffen Z. A., Hart S. L. (1993): 7-nitro indazole, an inhibitor of nitric oxide synthase, exhibits anti-nociceptive activity in the mouse without increasing blood pressure. Br. J. Pharmacol. 108, 296-297

Numagami Y., Zubrow A. B., Mishra O. P., Delivoria-Papadopoulos M. (1997): Lipid freeradical generation and brain cell membrane alteration following nitric oxide synthase 
inhibition during cerebral hypoxia in the newborn piglet. J. Neurochem. 69, 1542-1547

Ono Y., Ono H., Matsuoka H., Fujimori T., Frohlich E. D. (1999): Apoptosis, coronary arterial modeling, and myocardial infarction after nitric oxide inhibition in SHR. Hypertension 34, 609-616

Pan L., Zhang X., Song K., Wu X., Xu J. (2008): Exogenous nitric oxide-induced release ofcalcium from intracellular $\mathrm{IP}_{3}$ receptor-sensitive stores via S-nitrosylation in respiratory burst-dependent neutrophils. Biochem. Biophys. Res. Commun. 377, 1320-1325; doi:10.1016/ j.bbrc.2008.11.001

Persson A. E., Ollerstam A., Liu R., Brown R. (2004): Mechanisms for macula densa cell release of renin. Acta Physiol. Scand. 181, 471-474; doi:10.1111/j.1365-201X.2004.01320.x

Pessah I. N., Schiedt M. J. (1990): Early over-expression of lowaffinity $[3 \mathrm{H}]$ ryanodine receptor sites in heavy sarcoplasmic reticulum fraction from dystrophic chicken pectoralis major. Biochim. Biophys. Acta 1023, 98-106; doi:10.1016/0005-2736(90)90014-F

Sun M., Zhao Y., Gu Y., Xu C. (2008): Inhibition of nNOS reduces ischemic cell death through down-regulating calpain and caspase 3 after experimental stroke. Neurochem. Int. 54, 339-346; doi:10.1016/j.neuint.2008.12.017

Takabatake T., Ushiogi Y., Ise T., Kobayashi K. (1993): Effect of calcium antagonist, spontaneously hypertensive rats. Am. Heart J. 125, 578-581; doi:10.1016/0002-8703(93)90206-O

Takuma K., Matsuda T., Hashimoto H., Kitanaka J., Asano S., Kishida Y., Baba A. (1996): Role of $\mathrm{Na}^{+}-\mathrm{Ca}^{2+}$ exchanger in agonist-induced $\mathrm{Ca}^{2+}$ signaling in cultured rat astrocytes. J. Neurochem. 5, 1840-1845

Thorup C., Persson A. E. (1996): Impaired effect of nitric oxide synthesis inhibition on tubuloglomerular feedback in hypertensive rats. Am. J. Physiol. 271, F246-252

Tojo A., Kimoto M., Wilcox C. S. (2000): Renal expression of constitutive NOS and DDAH: separate effects of salt intake and angiotensin. Kidney Int. 58, 2075-2083; doi:10.1111/ j.1523-1755.2000.00380.x

Wagner C., Gödecke A., Ford M., Schnermann J., Schrader J., Kurtz A. (2000): Regulation of renin gene expression in kidneys of eNOS- and nNOS-deficient mice. Pflügers Arch. 439, 567-572; doi:10.1007/s004240050979

Wang M., Chen Z., Xing Y., Zhang X., Dong X.-Z., Ji G.-J. (2006): Localized $\mathrm{Ca}^{2+}$ uncaging induces $\mathrm{Ca}^{2+}$ release through $\mathrm{IP}_{3} \mathrm{R}$ in smooth muscle. Acta Pharmacol. Sin. 27, 939944; doi:10.1111/j.1745-7254.2006.00389.x

Wangensteen R., Sainz J., Rodríguez-Gomez I., Moreno J. M., Osuna A., Vargas F. (2003): Chronic blockade of neuronal nitric oxide synthase does not affect long-term control of blood pressure in normal, saline-drinking or deoxycorticosterone-treated rats. Exp. Physiol. 88, 243-250; doi:10.1113/eph8802489

Welch W. J., Tojo A., Lee J. U., Kang D. G., Schnackenberg C. G., Wilcox C. S. (1999): Nitric oxide synthase in the JGA of the SHR: expression and role in tubuloglomerular feedback. Am. J. Physiol. 277, F130-138

Welch W. J., Tojo A., Wilcox C. S. (2000): Roles of NO and oxygen radicals in tubuloglomerular feedback in SHR. Am. J. Physiol. 278, F769-776

Wilcox C. S., Welch W. J., Murad F., Gross S. S., Taylor G., Levi R., Schmidt H. H. (1992): Nitric oxide synthase in macula densa regulates glomerular capillary pressure. Proc. Natl. Acad. Sci. U.S.A. 89, 11993-11997; doi:10.1073/ pnas.89.24.11993

Zahradníková A., Križanová O. (1997): Nitric oxide and its effects on the calcium transport systems in the myocardium. Gen. Physiol. Biophys. 16, 197-214

Zanelli S. A., Ashraf Q. M., Mishra O. P. (2002): Nitration is a mechanism of regulation of the NMDA receptor function during hypoxia. Neuroscience 112, 869-877; doi:10.1016/ S0306-4522(02)00141-0

Zubrow A. B., Delivoria-Papadopoulos M., Ashraf Q. M., Ballesteros J. R., Fritz K. I., Mishra O. P. (2002): Nitric oxide-mediated expression of Bax protein and DNA fragmentation during hypoxia in neuronal nuclei from newborn piglets. Brain Res. 954, 60-67; doi:10.1016/S0006-8993(02)03342-5

Received: Marec 3, 2009

Final version accepted: April 16, 2009 